\title{
Effects of Surface Pre-treatment on the Nitrided Layers Properties
}

\author{
Mohamed Ali Terres, Brahim Ben Fathallah, Abdelkarim Ghanem \\ Laboratory Mechanics, Materials and Processes (LMMP) ENSIT, University of Tunis, Tunis, Tunisia \\ Email address: \\ mohamedali_terres@yahoo.fr (M. A. Terres)
}

\section{To cite this article:}

Mohamed Ali Terres, Brahim Ben Fathallah, Abdelkarim Ghanem. Effects of Surface Pre-treatment on the Nitrided Layers Properties. American Journal of Mechanical and Industrial Engineering. Vol. 2, No. 1, 2017, pp. 41-47. doi: 10.11648/j.ajmie.20170201.17

Received: August 12,2016; Accepted: August 25, 2016; Published: January 4, 2017

\begin{abstract}
In this work the 42CrMo4 steel ground surface integrity was evaluated at different grinding conditions before and after nitriding. An experimental study was carried out to investigate the influence of depth of cut on work piece surface integrity by grinding. Surface integrity was characterized by roughness, micro-hardness, residual stress distribution and ground surface morphology. These properties were compared to nitriding state. These improvements in grindability and in surface integrity are particularly favoured by low depth of cut values. It is also shown that these improvements are essentially due to the reduction of the grinding temperature, which decrease the tensile residual stresses and favours the material removal by shearing and limits the ground surface damage. The roughness of the ground work piece surfaces increases with the depth of cut, which was attributed to plastically deformed coatings on the work piece surface occurring with elevated temperature. The results presented in this study shows that the material history before nitriding does not have any influence on the residual stresses distribution after nitriding. This is due to that during the nitriding treatment, especially in the heating phase; the tensile stresses generated by grinding are cancelled under the temperature effect.
\end{abstract}

Keywords: Grinding, Nitriding, Surface Defects, Surface Roughness, Residual Stress, Work Hardening

\section{Introduction}

It has been shown that the fatigue life improvement of steels by the nitriding treatments depend on the characteristics of the nitrided layers, in particular of the residual stresses distributions and the work hardening [1-3]. It is also reported that these characteristics depend on the treatment conditions (lasted, atmosphere and temperature), on steel nature and in particular its contents of alloy elements contributing to the nitride formation and thus controlling their residual stresses level and in consequence their resistance to the fatigue crack initiation. The fatigue performances of the superficially treated parts depend closely on the hardened layers quality: the metallurgical structure, the hardening and the residual stresses state. [3-9]

The surfaces preparation mode before nitriding, the surface layers preliminary characteristics and their eventual effect on the resistance to fatigue were not approached in the literature. Indeed the initial state of surfaces and superficial layers before nitriding treatment was seldom described in the total of the references concerning the nitriding treatments. Its eventual effect on the nitrided layers characteristics and its consequences on their integrity under the cyclic loading conditions were the subject of no targeted study. In this work we are interested in the preparation mode by grinding. One target the grinding preparation mode explores three cutting conditions by this process, supposed to confer on the surface layers of the very different initial characteristics. One then seeks to evaluate the possible effects of the initial characteristics on those of the nitrided layers. In the literatures an overview of the process parameters used to optimize the ground surface quality shows that the grinding conditions have been intensively investigated $[10,11]$. The ground surface quality was usually characterized by its roughness, defects, residual stress distribution and phase transformation. The effects of the process parameters on these surface characteristics can be summarized as follows:

(i) The ground surface roughness and hardening are mainly controlled by the grinding conditions i.e. depth of cut $(a(\mu \mathrm{m}))$ work speed $(v w(\mathrm{~m} / \mathrm{min}))$ wheel peed $(v s(\mathrm{~m} / \mathrm{s})) ;[12,13]$ 
(ii) The residual stress distributions are largely affected by the grinding fluid type and the delivering conditions to the grinding zone, i.e. pressure, and the abrasive grain specifications. [14-16]

The present work is aimed at evaluating the grindability and the surface integrity of the $42 \mathrm{CrMo} 4$ steel. We explore three cutting conditions, supposed to confer to the superficial layers, very different initial characteristics. Then we try to evaluate the eventual effects of the initial characteristics on those of the layers treated by nitriding. The surface integrity was assessed by the structural and metallurgical transformations, the induced work hardening, the residual stresses levels and the surface morphology. These parameters were selected as they are thought to be the main factors controlling the in-service behaviour of the $42 \mathrm{CrMo} 4$ steel.

\section{Experimental Techniques}

\subsection{Work Piece Material}

The work piece material used for the experiments was the $42 \mathrm{CrMo} 4$ steel. Table 1 and 2 give its chemical composition and its mechanical properties at $20^{\circ} \mathrm{C}$. The material was quenched at $850^{\circ} \mathrm{C}$, cooled in oil and tempered at $580^{\circ} \mathrm{C}$. Fig. 1 shows a micrograph of the $42 \mathrm{CrMo} 4$ microstructure; the metallurgical structure obtained is a tempered martensite.

Table 1. Chemical composition of studied steel.

\begin{tabular}{|c|c|c|c|c|c|c|c|c|c|c|c|c|}
\hline $\mathrm{C}$ & Mn & $\mathbf{S i}$ & $\mathbf{S}$ & $\mathrm{Cr}$ & $\mathbf{P}$ & Mo & $\mathbf{N i}$ & Al & $\mathrm{Cu}$ & V & $\mathbf{T i}$ & $\mathrm{Fe}$ \\
\hline 0.41 & 0.77 & 0.28 & 0.026 & 1.02 & 0.019 & 0.16 & 0.16 & 0.04 & 0.25 & $<0.01$ & 0.03 & bal. \\
\hline
\end{tabular}

Table 2. Mechanical properties of the $42 \mathrm{CrMo} 4$ steel at $20^{\circ} \mathrm{C}$

\begin{tabular}{lllll}
\hline Yield stress (MPa) & Ultimate tensile stress (MPa) & A (\%) & Young modulus (GPa) & Micro-hardness HV \\
\hline 950 & 1080 & 17.5 & 201 & 356 \\
\hline
\end{tabular}

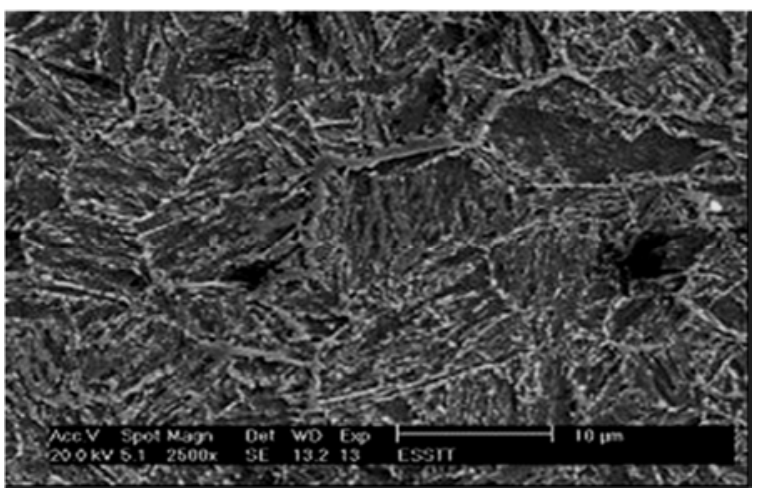

Fig. 1. Tempered martensite structure of the untreated state.

\subsection{Grinding Tests}

All the grinding tests were performed in down cut plunge surface grinding mode using a Teknoscuola RT600 grinding machine. As for the selection of the grinding conditions (table 3), previous investigations have discussed the surface integrity improvements depending on the depth of cut (low, deep and high). The experimental work conducted in the present study aims to enhancing the findings of previous investigations.

Table 3. Experimental conditions.

\begin{tabular}{ll}
\hline Grinding mode & Plunge surface grinding, down cut \\
\hline Grinding wheel & $99 \mathrm{~A} 46 \mathrm{H} 7 \mathrm{VNE}$ \\
Wheel speed (Vs) & $30 \mathrm{~m} / \mathrm{s}$ \\
Work speed (vw) & $6 \mathrm{~m} / \mathrm{min}$ \\
Depth of cut (a) & $0.100 ; 0.050 ; 0.030 \mathrm{~mm}$ \\
Environments & Soluble oil $(20 \%), 7.21 / \mathrm{min}$ \\
Work piece material & $42 \mathrm{CrMo} 4$ steel \\
Dresser & Single point diamond dresser \\
Dressing depth & $0.01 \mathrm{~mm}$ \\
\hline
\end{tabular}

\subsection{Testing Method}

The surface roughness was evaluated using a Hommel tester T1000 stylus-type profilometer. The structural modifications were observed using a scanning electron microscopy (SEM). The surface work hardening was evaluated by micro-hardness measurements using a Shimadzu micro-hardness tester HMV2000 and the near surface residual stress were evaluated using the tilt X-ray method by means of a SET-X type diffractometer under the conditions listed in table 4 . The residual stress profiles were established using the hole drilling method. The holes were drilled incrementally by a $2 \mathrm{~mm}$ diameter drill rotating at a high speed $(2500 \mathrm{rpm})$ to avoid inducing additional residual stresses.

Table 4. X-ray diffraction conditions.

\begin{tabular}{ll}
\hline Target & Cr \\
\hline Wavelength $\left(\mathrm{A}^{\circ}\right)$ & 2.2897 \\
Filtre & $\mathrm{V}$ \\
Curent $(\mathrm{mA})$ & 5 \\
Voltage $(\mathrm{kV})$ & 20 \\
Goniometer tilt & $\psi$ \\
Young's modulos, E $(\mathrm{GPa})$ & 210 \\
Poisson's ratio, $v$ & 0.33 \\
Number of $\psi$ angles & $13\left(\right.$ from $-36.3^{\circ}$ to $\left.+39.2^{\circ}\right)$ \\
Number of $\theta$ angles & $2\left(0^{\circ}\right.$ and $\left.90^{\circ}\right)$ \\
\hline
\end{tabular}

\subsection{Treatment of Nitriding}

One series of specimens were submitted to surface treatment by gas nitriding; the parameters of this treatment are reported in table 5 . 
Table 5. Nitriding conditions.

\begin{tabular}{llll}
\hline Nitriding type & Temperature $\left({ }^{\circ} \mathbf{C}\right)$ & Duration $(\mathbf{H})$ & $\begin{array}{l}\tau^{*}=\mathbf{P}_{\mathrm{NH} 3} / \\
\left(\mathbf{P}_{\mathbf{H}}\right)^{\mathbf{1 , 5}}(\mathbf{\%})\end{array}$ \\
\hline Gas & 520 & 36 & 35 \\
\hline
\end{tabular}

\section{Results}

\subsection{Effects of the Depth of Cut on the 42CrMo4 Steel Ground Surface Integrity}

\subsubsection{Effects on the Surface Defects}

SEM observations of the ground surface generated under fine grinding conditions show that these surfaces are exempt from thermal defects (Fig. 2). These surface defects are all the more perceptible since the depth of cut is higher. However, surface generated under coarse grinding conditions are characterized by surface gunning and thermal microcracks having a length varying from. A quantitative evaluation of these crack distributions shows that the crack density increases with the increase of the depth of cut.
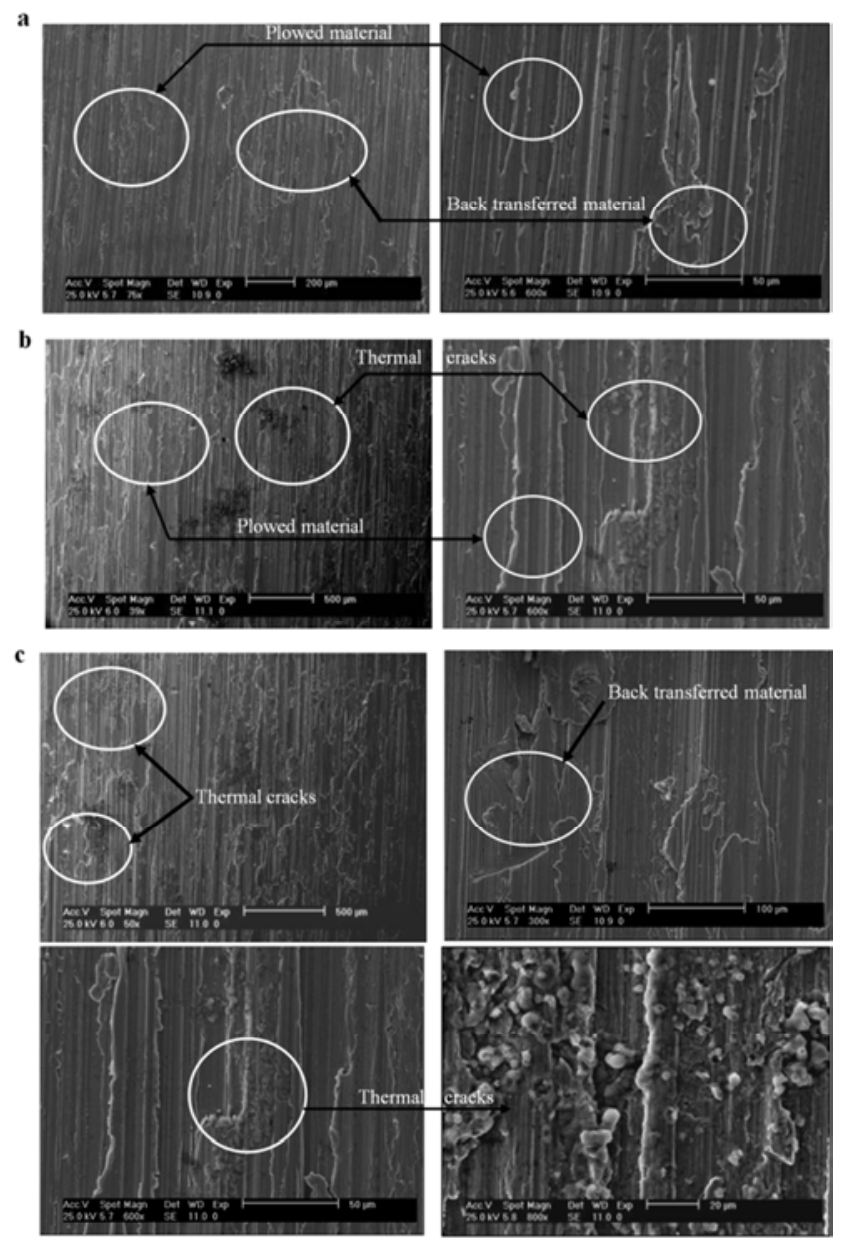

Fig. 2. Effects of the depth of cut on the ground surface morphology (a) Low condition $(a=30 \mu \mathrm{m})$; (b) Deep condition $(a=50 \mu \mathrm{m})$; (c) High condition $(a=100 \mu \mathrm{m})$.

\subsubsection{Surface Roughness}

The micro-geometrical quality of the ground surface was characterized by the arithmetic $(R a(\mu \mathrm{m}))$ and the total
$(R t(\mu \mathrm{m}))$ roughness parameters. Fig. 3 shows the variation of these parameters function of the depth of cut. As noticed above, that the parameters of roughness, arithmetic and total, are definitely weaker for the depths of cut $30 \mu \mathrm{m}$ and $50 \mu \mathrm{m}$. The depth of cut was limited to $0.1 \mathrm{~mm}$ because of the excessive burning of the ground surface even though burning traces started to appear at a depth of cut around $0.05 \mathrm{~mm}$. However, for depths of cut higher than this critical value, these process parameters are seen to affect significantly $R a$ and $R t$.

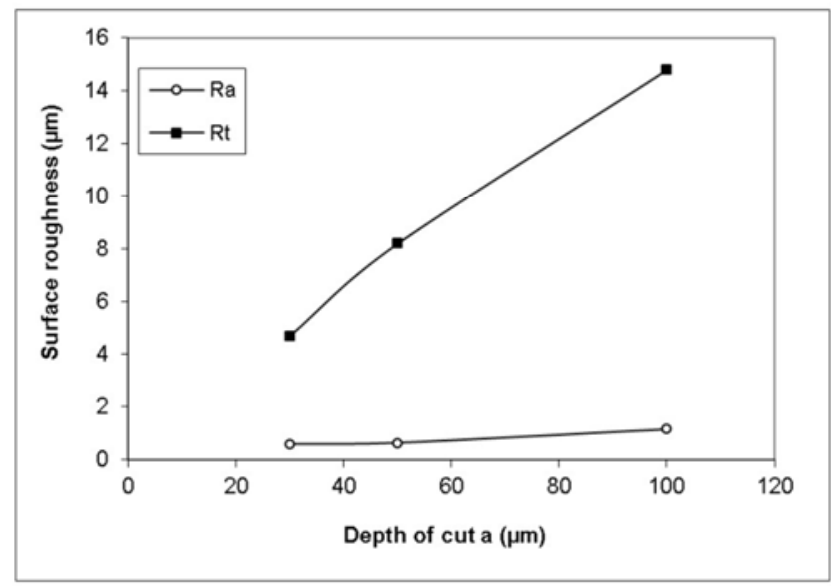

Fig. 3. Effects of depth of cut on the ground surface roughness.

\subsubsection{Work-Hardening}

Micro-hardness measurements at a cross section of the ground specimens show that material softening took place. The micro-hardness profiles given by fig. 4 show that work softening takes place at the ground surface upper layers at a depth of around $300 \mu \mathrm{m}$. This work softening, which increases with the increase of depth of cut, is generated by tempering, that results from the high thermal effects that took place at the grinding zone. The grinding process induces an increase in the hardness of the outer layers, of machined surfaces.

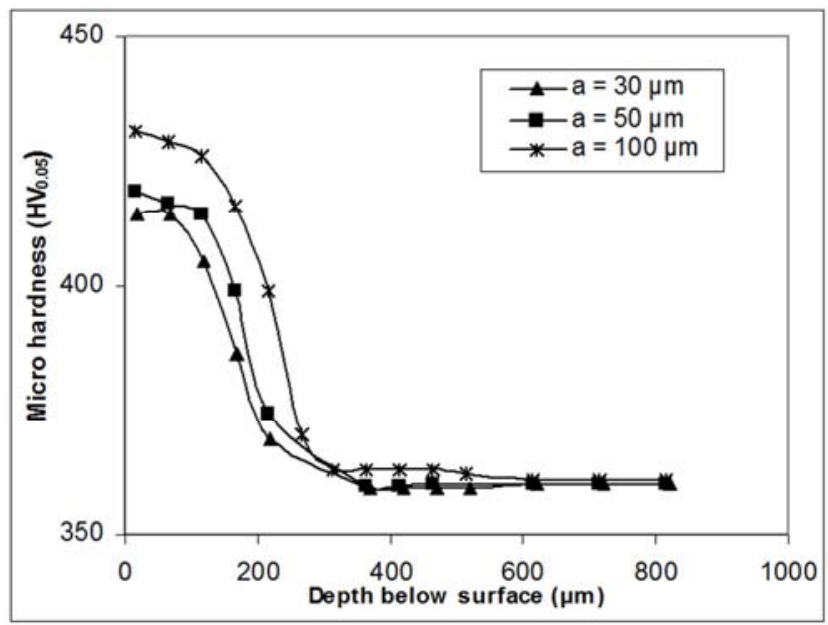

Fig. 4. Effects of the depth of cut on the micro-hardness depth-profiles.

The comparison of the micro hardness profiles, reveals 
maximum values in under layers; they vary between $400 \mathrm{HV}$ for depth of cut: $a=30 \mu \mathrm{m}$ and $430 \mathrm{HV}$ for depth of cut: $a=$ $100 \mu \mathrm{m}$. The profiles relating to the various preliminary surfaces preparation modes are almost superposable.

\subsubsection{Residual Stresses}

(i) At surface:

The deformations incompatibilities between surface and core of the grinding parts under loading conditions (thermal and mechanical) associated to the grinding process generate tensile residual stresses. The determination of the residual stresses on the surface was carried out, in the two grinding directions, in parallel $\left(\sigma_{0}\right)$ and perpendicularly $\left(\sigma_{90)}\right.$ with the grinding directions.

Results of near surface residual stress measurements in parallel and perpendicular directions to the grinding grooves (Fig. 5).

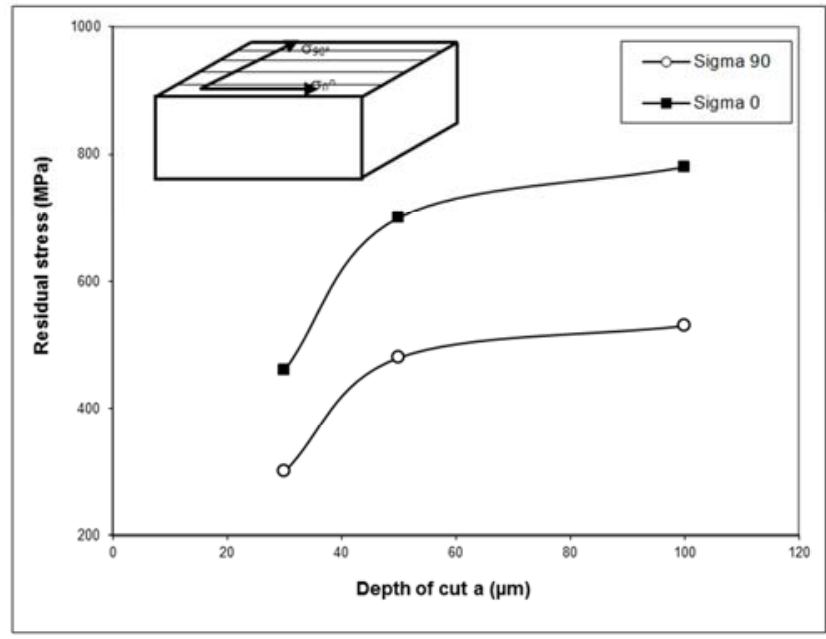

Fig. 5. Effects of the depth of cut on the residual stresses at surface.

It reveals that the residual stresses on the surface evolve according to the depth of cut. They vary between $+471 \mathrm{MPa}$ for depth of cut: $a=30 \mu \mathrm{m}$ and $+769 \mathrm{MPa}$ for depth of cut: $a=$ $100 \mu \mathrm{m}$.It is also seen that the amplitude in parallel direction are much higher than in perpendicular one.

(ii) Residual stresses profiles:

The residual stresses profiles given by fig. 6 , are obtained for work piece under conditions. These profiles show that the highest levels of the residual stresses. The residual stresses profiles in a grinding state reveal a gradient of residual stresses in the hardened layers from surface towards the core. In results, maximum values of tensile slightly reached in under layer (approximately $0.1 \mu \mathrm{m}$ ) and depths of tensile layers depending on the depth of cut were observed. $(0.6 \mathrm{~mm}$ for a depth of cut: $a=30 \mu \mathrm{m}$ and $0.8 \mathrm{~mm}$ for a depth of cut: $a$ $=100 \mu \mathrm{m}$ (fig. 6)). Other parameters, such as the maximum stress value and the width of the stress profile, seem to depend only on the thermo-physical behaviour of the machined material. High level tensile residual stresses induce micro-cracks at the surface.

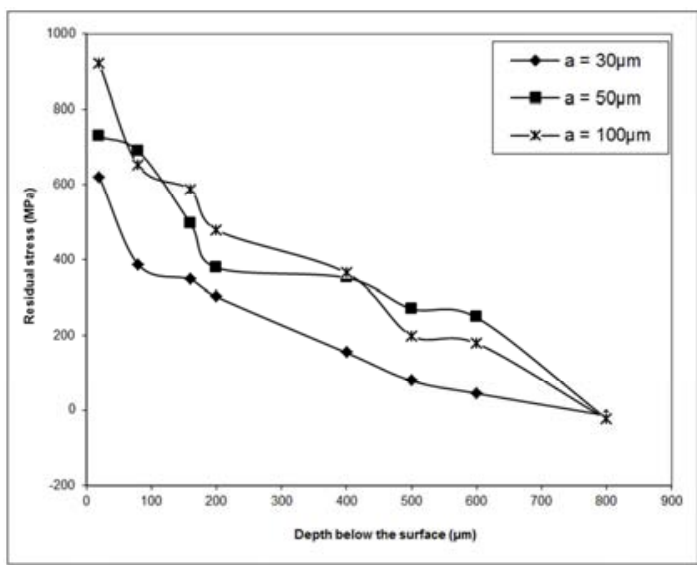

a

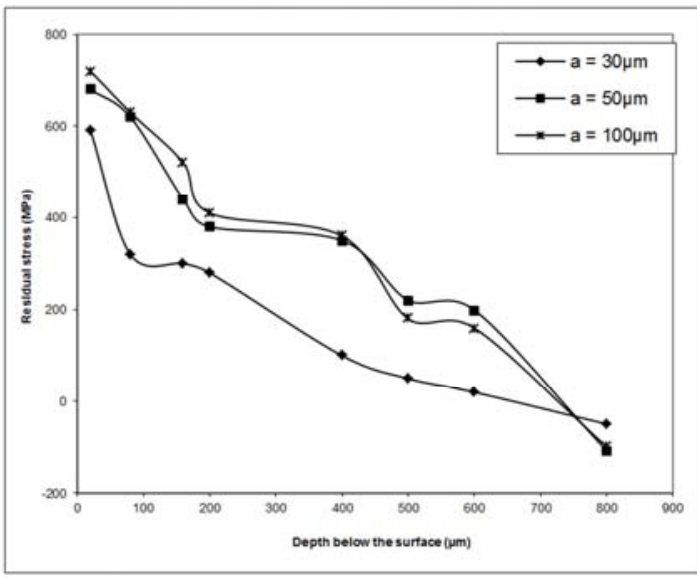

Fig. 6. Effects of the depth of cut on the residual stresses profiles: (a) Parallel on grinding direction; (b) Perpendicular on grinding direction.

\subsection{Effect of the Gas Nitriding on the Surface Integrity}

\subsubsection{Micro Structural Characterisation}

The metallurgical investigations carried out on the surface layer (fig. 7) and scanning electron microscopy SEM (Fig. 8), show the existence of a compound layer approximately $11 \mu \mathrm{m}$ in thickness, made up of two phases, $\gamma^{\prime}\left(\mathrm{Fe}_{3-4} \mathrm{~N}\right)$ and $\varepsilon\left(\mathrm{Fe}_{2}-\mathrm{N}\right)$, and a hardened diffusion layer about $350 \mu \mathrm{m}$ in thickness. SEM photo-graphs of the gas-nitrided surface revealed the formation of many small conical asperities (fig. 9).

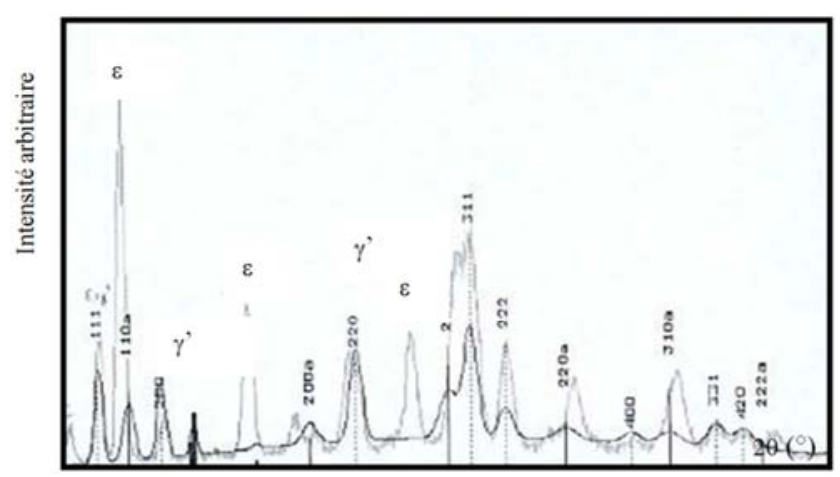

Fig. 7. X-ray analysis of the surface layer. 


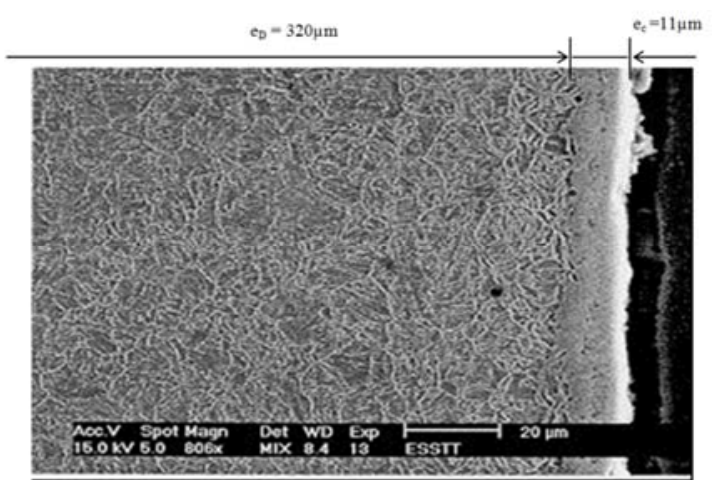

Fig. 8. Metallurgical microstructure of the surface layer observed by SEM.

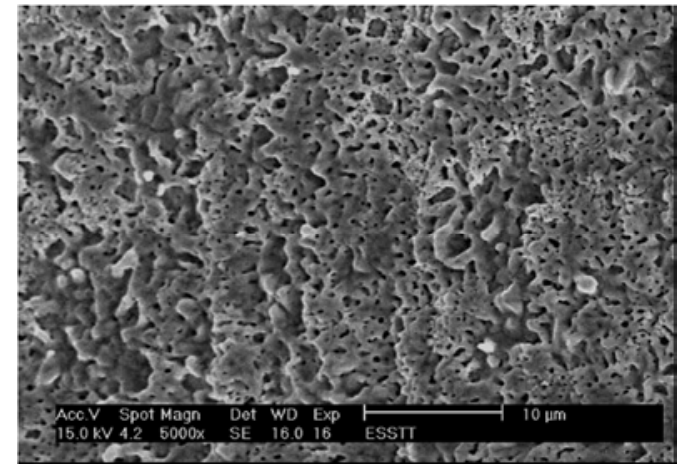

Fig. 9. Compound layer morphology.
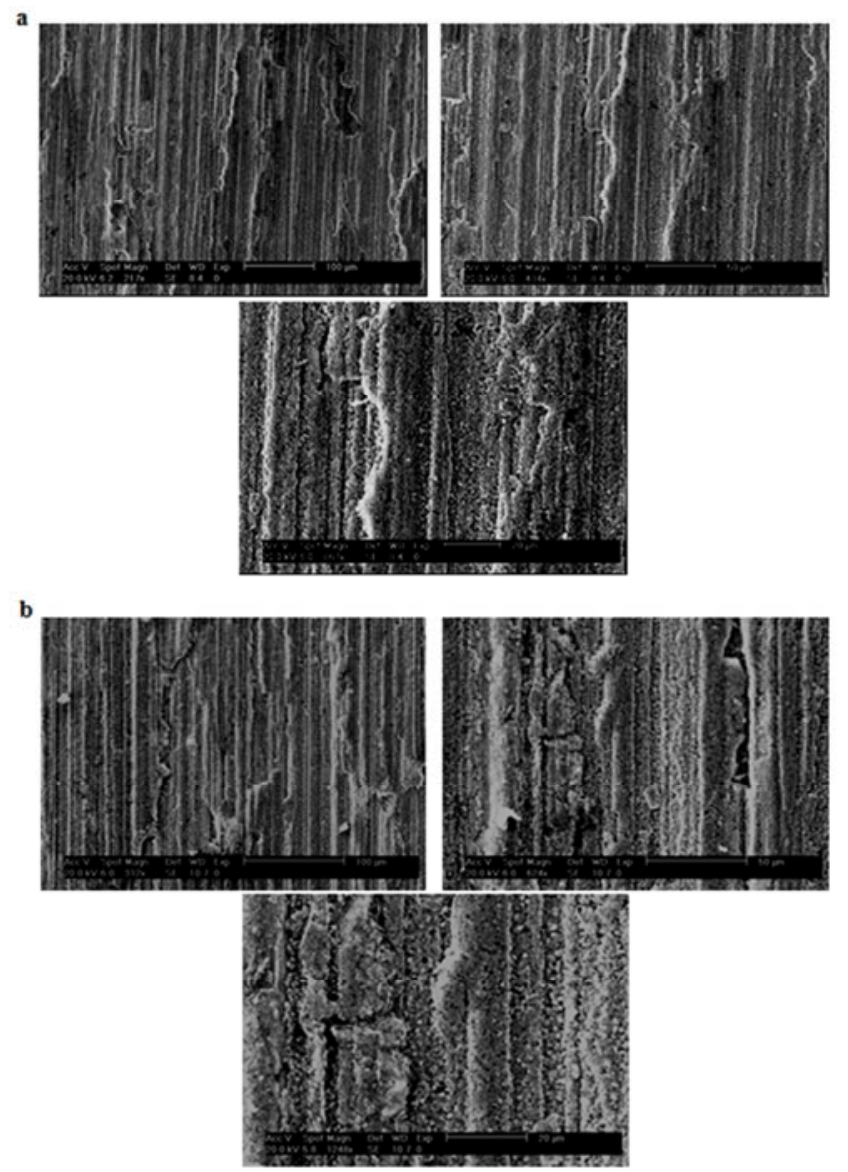

Fig. 10. Effects of nitriding on the surface morphology. (a) Deep condition a $=50 \mu \mathrm{m} ;$ (b) High condition $a=100 \mu \mathrm{m}$

\subsubsection{Effects on the Surface Defects}

The SEM observation, of the nitrided surfaces ground with depths of cut $\mathrm{a}=30 \mu \mathrm{m}, \mathrm{a}=50 \mu \mathrm{m}$ and $\mathrm{a}=100 \mu \mathrm{m}$, shows the same aspect compared to that of untreated parts, in addition to another typical granulated aspect of micro porosities associated with the compound layer (fig. 10).

\subsubsection{Surface Roughness}

The roughness measurements, which are similar to those of the initial state, confirm well these observations, as shows the comparative data of table 6.

Table 6. Comparison of (Ra) and (Rt) values of the various studied states.

\begin{tabular}{lllll}
\hline $\begin{array}{l}\text { Depth of cut a } \\
(\boldsymbol{\mu m})\end{array}$ & $\mathbf{R a}(\boldsymbol{\mu m})$ & \multicolumn{3}{c}{ Rt $(\boldsymbol{\mu m})$} \\
\cline { 2 - 5 } & Nitrited & Untreated & Nitrited & Untreated \\
\hline 30 & 0.55 & 0.6 & 4.15 & 4.67 \\
50 & 0.61 & 0.63 & 7.30 & 8.2 \\
100 & 1.14 & 1.16 & 13.78 & 14.78 \\
\hline
\end{tabular}

\subsubsection{Work-Hardening}

Vickers micro-hardness was evaluated at the cross-section of the nitrided specimens. The results are plotted in fig. 11 against the distance from the surface. A maximum value of hardness of about $1000 \mathrm{HV}$ was observed near the surface within the compound layer. In the diffusion layer, the hardness decreases with the distance from the surface. For depths above $0.6 \mathrm{~mm}$, the hardness remains at $355 \mathrm{HV}$. The micro-hardness measurements were repeated for several specimens and no significant differences were found.

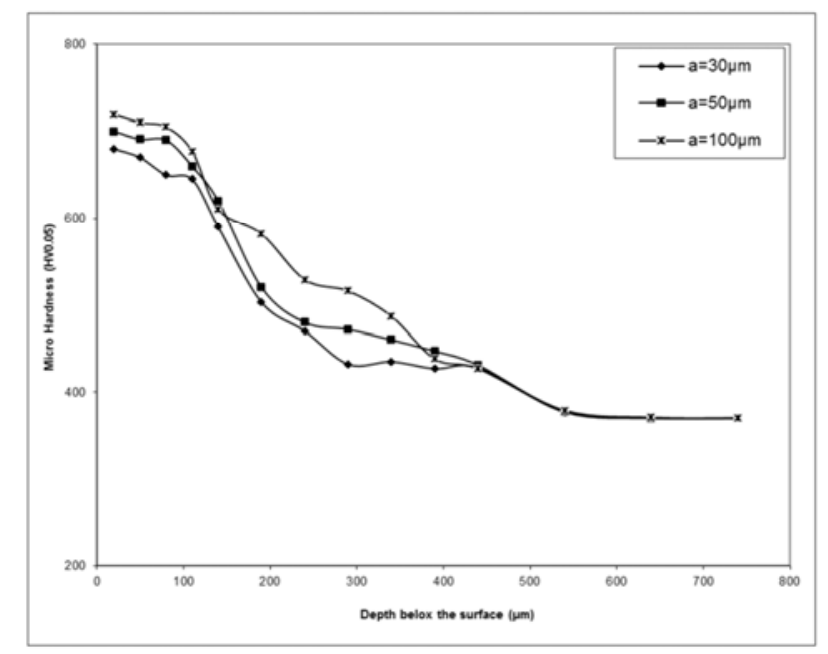

Fig. 11. Effects of the nitriding on the micro-hardness depth-profiles.

The comparison of the micro-hardness profiles, reveals maximum values in under layers; were noted for the various depths of cut since these values vary between 680HV for $a=$ $30 \mu \mathrm{m}$ and $720 \mathrm{HV}$ for $a=100 \mu \mathrm{m}$. This confirms the negligible effect of the grinding conditions on the characteristics of the nitrided layers

\subsubsection{Residual Stresses}

The X-rays diffraction measurements of the residual stresses reveal a weak dependence with respect to the former state of preparation. Only ordering biases of uncertainties of 
measurement were noted for the various depths of cut preceding nitriding (fig. 12).

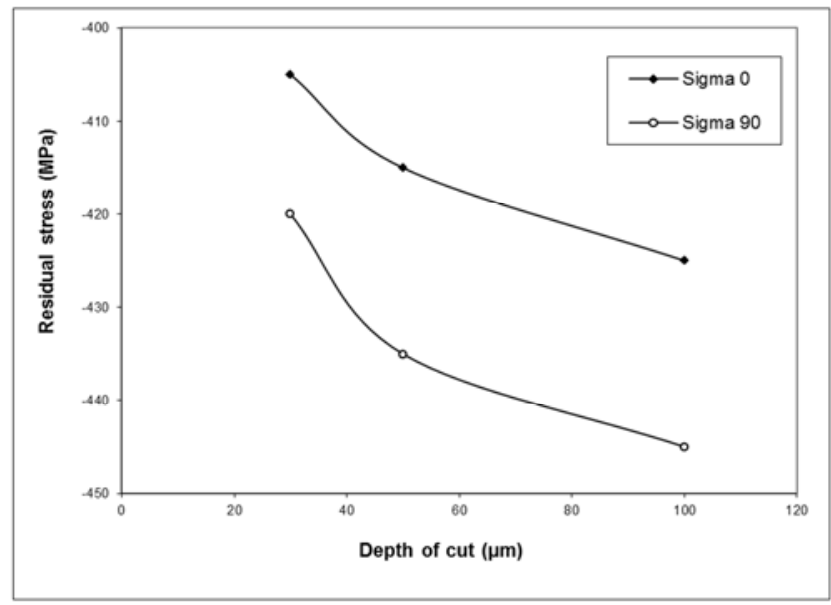

Fig. 12. Effects of the depth of cut on the residual stresses at surface.

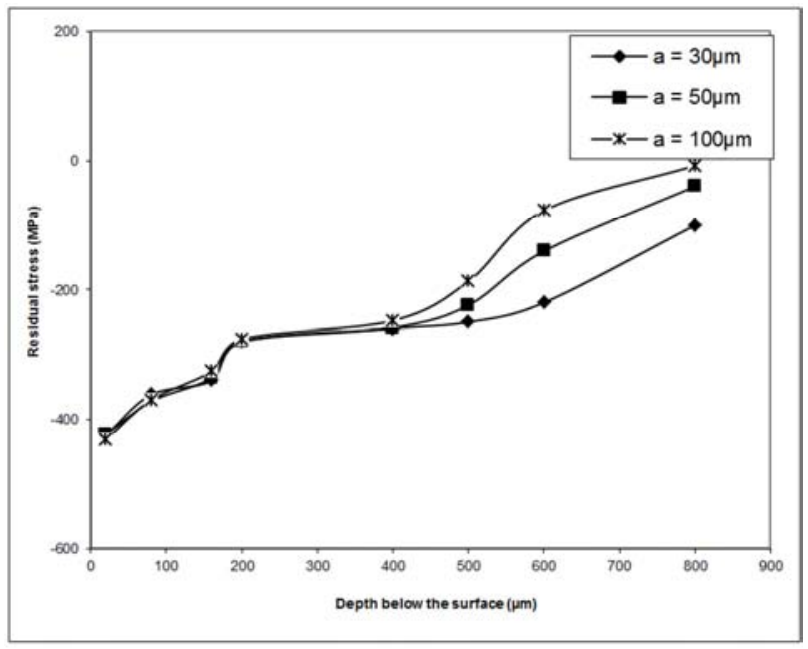

a

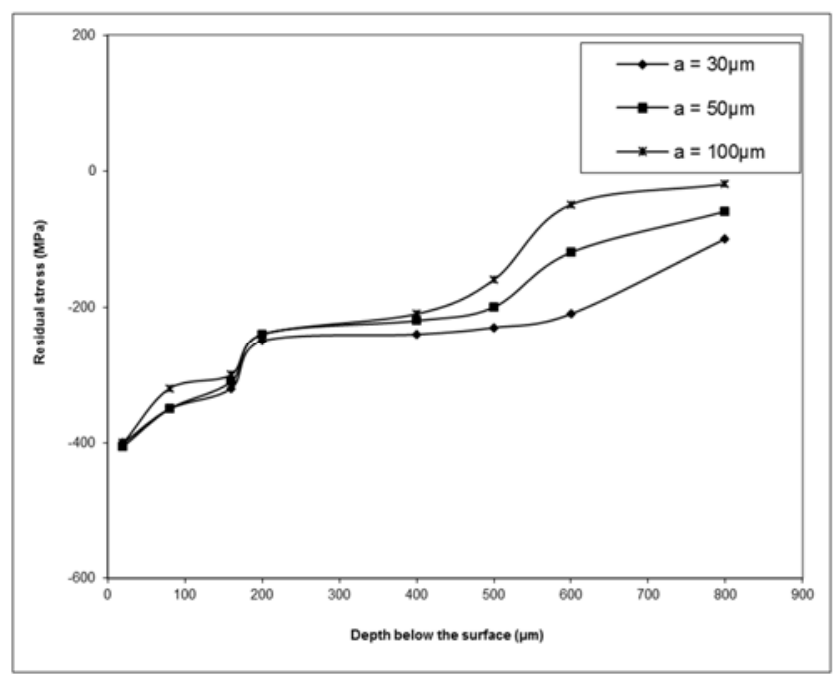

b

Fig. 13. Effects of nitriding on the residual stresses profiles(a) Parallel on grinding direction; (b) Perpendicular on grinding direction.
The comparison of the profiles of residual stresses reveals values of compressive stress which evolve when approaching the heart. This for the various grinding conditions (fig. 13). The profiles relating to the various preliminary surfaces preparation modes (various depths of cut) are almost superposable. This confirms the negligible effect of the grinding conditions on the nitrided layers characteristics and on the residual stresses distribution.

\section{Discussion}

The most significant improvements can be summarized as follow:

Taking into account for the surfaces roughness mechanisms, the ground work piece surface morphologies having different colours were examined using SEM. It can be seen that the ground surface having normal colour is relatively smooth and consists mostly of overlapping scratches produced by interactions of abrasive cutting points with the work piece. Compared with the surface having normal colour, the morphology of other surfaces become more complicated, in that some kind of plastically deformed coatings appear and gradually spread on the ground work piece surfaces with an increasing temperature. Moreover, micro-cracks are found on the work piece surface and indicate severe damage to the ground surface.

It can also be seen that the zones in which residual stresses and micro-hardness change obviously, are similar to the affected depth of the plastically deformed coatings. The plastic deformation generated in the grinding process increase of micro-hardness in the areas near to the ground surface due to the processing hardening effect. The plastically deformed coatings, which directly roughen the ground surfaces, can be removed in the second stage at a much smaller removal rate, since the thermally affected zones are within $40 \mu \mathrm{m}$, which is much smaller compared with the depth of cut adopted in fine grinding.

In grinding, it is well known that while the tensile residual stresses are the subsequence of the thermally induced stresses and deformations associated with the grinding temperature. But, the compressive residual stresses are caused by the mechanical effects induced by the grinding forces. It is also known that for grinding with conventional abrasives, the resulting residual stresses are usually tensile. Tensile residual stress distribution results from incompatibility between plastic deformations generated by the machining process. These plastic deformations results from expansions due to the thermal gradient, and from volume changes due to chemical and structural modifications. The contribution of metallurgical transformations in the formation of residual stresses explains, in large part, the difference between stress profiles machined under the same depth of cut. This result has been observed in the previous studies with some other materials and different machining conditions [10,11, 14, 15, and 16].

The results of this study show that the nitriding conditions introduce metallurgical modifications into the superficial layers of steel $42 \mathrm{CrMo} 4$, characterized by the appearance of 
a white layer (constituted by nitrides $\gamma^{\prime}$ and / or $\varepsilon$, such as $e_{C}$ $=11 \mu \mathrm{m}$ ) and a diffusion layer (solid solution of nitrogen in insertion, such as $\left.e_{D}=350 \mu \mathrm{m}\right)$ having characteristics different to those of the initial layers before treatment (work hardening, hardening, distribution of the residual stresses). This corresponds to grinding states under various conditions. This comes owing to the fact that:

(i) The nitriding does not have any effect on the microgeometrical surfaces characteristics (unchanged roughness after nitriding);

(ii) The hardening obtained after nitriding is essentially associated to the phase shifts (appearance of the white layer) and hardening by an insertion solid solution of nitrogen in the diffusion layer. It is well established that the metallurgical change is essentially controlled by the nitriding conditions [4-6, $8,9]$.Thus, the state of initial hardening associated exclusively with work hardening by grinding does not have any effect on structural work hardening resulting from nitriding;

(iii) The residual stresses distribution after nitriding is the result of the metallurgical transformations, which have taken place during nitriding, and of the deformations resulting from cooling after nitriding. So they have origins different to those of the grinding state and do not seem dependent on any distribution associated with preliminary surface preparation mode. Only the metallurgical transformation amplitude (dependent on the nitriding conditions) and the cooling modes after nitriding, control the residual stresses distribution in the nitrided layers. This report was confirmed by the results of this study.

\section{Conclusion}

In this paper the effects of the depth of cut and nitriding on the surface integrity was investigated. It was found that the metallurgical transformation, the surface hardening und the surface residual stress are mainly controlled by the depth of cut. The main results can be summarized as follows:

(i) Surface with lower roughness are generated when the grinding under low depth of cut comparatively with the deep or high depth of cut;

(ii) Less tensile residual stress was measured for low depth of cut. This was attributed to favours the ship formation by shearing and reduces the friction between the formed chips and the ground surface;

(iii) In this investigation, like all the grinding tests were conducted with very close values of the stock removal rate, the improvements indicated above are favoured by grinding parameters using low depth of cut;

(iv) The characteristics of the nitrided layers (work hardening, hardening and residual stresses distribution) are independent to those of the ground layers before treatment.

\section{References}

[1] F. Ashrafizadeh, Influence of plasma and gas nitriding on fatigue resistance of plain carbon (C45) steel. Surface and Coatings Technology 173-174 (2003), 1196-1200.
[2] M. A. Terres, S. Ben Mohamed and H. Sidhom: Influence of ion nitriding on fatigue strength of low-alloy (42CrMo4) steel: Experimental characterization and predictive approach. International Journal of Fatigue, 2010, 9: 42-56.

[3] A. Alsaran, M. Karakan, A. Celik, The investigation of mechanical properties of ion-nitrided AISI 5140 low-alloy steel. Material Characterization 48 (2002) 323-327.

[4] K. S. Jung, R. E. Schacherl, E. Bischoff, E. J. Mittemeijer, Nitriding of FerriticFe-Cr-Al Alloys. Surface. Coating Technology, Vol 204 (2010) 1942-1946

[5] N. Limodin and Y. Verreman: Fatigue Strength Improvement of a 4140 Steel by Gas Nitriding: Influence of Notch Severity. Materials Science and Engineering A, 2006, 435-436: 460467.

[6] G. A. Webster, A. N. Ezilo, Residual stress distributions and their influence on fatigue life times. International Journal of Fatigue 23 (2001) S375-S383

[7] B. Y. Jeong, M. H. Kim, Effects of the process parameters on the layer formation behavior of plasma nitrided steels. Surface and coatings Technology 141 (2001) 182-186.

[8] E. J. Mittemeijer, Max Planck, Fundamentals of Nitriding and Nitrocarburizing. ASM Handbook,Steel Heat Treating Fundamentals and Processes, Volume 4A (2013) 619-645.

[9] H. Selg, E. Bischoff, I. Bernstein,T. Woehrle, S.R. Meka, Defect-Dependent Nitride Surface-Layer Development upon Nitriding of Fe-1at.\%Mo Alloy. Philos. Mag., Vol 93 (2013)2133-2160

[10] G.F. Li, L. S. Wang, L. B Yang, Multi parameter optimization and control of the cylindrical grinding process. Journal of Materials Processing Technology 129 (2002) 232-236.

[11] N. Ben Fredj, C. Braham, H. Sidhom, Ground surface improvement of the austenitic stainless steel AISI 304 using cryogenic cooling. Surface \& Coatings Technology 200 (2006) 4846-4860.

[12] A. Barbacki, M. Kawalec, A. Hamrol, Turning and grinding as a source of microstructural changes in the surface layer of hardened steel. Journal of Materials Processing Technology 133 (2003) 21-25.

[13] X. P. Xu, Y. Q. Yu \& H. J. Xu, Effect of grinding temperatures on the surface integrity of a nickel-based super alloy. Journal of Materials Processing Technology 129(2002) 359-363.

[14] B. Ben Fathallah, N. Ben Fredj, H. Sidhom, C. Braham \& Y. Ichida, Effects of abrasive type cooling mode and peripheral grinding wheel speed on the AISI D2 steel ground surface integrity. International Journal of Machine tools \& manufacture 49 (2009) 261-272.

[15] Bogdan W. Kruszynski, Ryszard Wojeik, Residual stress in grinding. Journal of Materials Processing Technology 109 (2001) 254-257.

[16] M. J. Balart, A. Bouzina, L. Edwards, M.E. Fitzapatrick, The onset of tensile residual stresses in grinding of hardened. Materials Science and Engineering 367A (2004) 12-142. 